\title{
An alternating iteration algorithm for solving the split equality fixed point problem with L-Lipschitz and quasi-pseudo-contractive mappings
}

\author{
Meixia Li ${ }^{1 *} \mathbb{D}$, Xueling Zhou² and Haitao Che
}

"Correspondence:

limeixia001@163.com

${ }^{1}$ School of Mathematics and

Information Science, Weifang University, Weifang, P.R. China

Full list of author information is

available at the end of the article

\begin{abstract}
In this paper, we are concerned with the split equality common fixed point problem. It is a significant generalization of the split feasibility problem, which can be used in various disciplines, such as medicine, military and biology, etc. We propose an alternating iteration algorithm for solving the split equality common fixed point problem with L-Lipschitz and quasi-pseudo-contractive mappings and prove that the sequence generated by the algorithm converges weakly to the solution of this problem. Finally, some numerical results are shown to confirm the feasibility and efficiency of the proposed algorithm.
\end{abstract}

MSC: 47J25; 47J20; 47H09

Keywords: Split equality common fixed point problem; Alternating iteration algorithm; Weak convergence

\section{Introduction}

Throughout this paper, we always assume that $H_{1}, H_{2}$ and $H_{3}$ are real Hilbert spaces with inner product $\langle\cdot, \cdot\rangle$ and induced norm $\|\cdot\|$. Let $C$ and $Q$ be nonempty closed and convex subsets of $H_{1}$ and $H_{2}$, respectively. Let $A: H_{1} \rightarrow H_{2}$ be a bounded linear operator and $I$ denote the identity operator. The split feasibility problem (SFP) is to find

$$
x \in C \quad \text { such that } A x \in Q \text {, }
$$

which is first introduced by Censor and Elfving [8] in finite-dimensional Hilbert spaces for modeling inverse problems. The applications of the split feasibility problem are very comprehensive such as $\mathrm{CT}$ in medicine, intelligence antennas and the electronic warning systems in militarily, the development of fast image processing technology, etc. [5, 7, 9, 34].

To solve the problem (1.1), Byrne [4] proposed the CQ algorithm which generates a sequence $\left\{x_{n}\right\}$ by

$$
x_{n+1}=P_{C}\left(x_{n}-\xi A^{*}\left(A x_{n}-P_{Q} A x_{n}\right)\right),
$$

(c) The Author(s) 2019. This article is distributed under the terms of the Creative Commons Attribution 4.0 International License (http://creativecommons.org/licenses/by/4.0/), which permits unrestricted use, distribution, and reproduction in any medium, provided you give appropriate credit to the original author(s) and the source, provide a link to the Creative Commons license, and indicate if changes were made. 
and proved the sequence generated by (1.2) converges to the solution of (1.1), where $A^{*}$ is the adjoint operator of $A, \xi \in(0,2 / L)$ and $L$ denotes the largest eigenvalue of the matrix $A^{T} A$. Furthermore, many authors studied the problem (1.1) and proposed some algorithms for solving it, please see $[3,6,22,25,26,32,33,35]$ and the references therein. Particular cases of the CQ algorithm are the Landweber and projected Landweber methods for obtaining exact or approximate solutions of the linear equations $A x=b$.

In $[18,19,24,30,31,34]$, a lot of algorithms were proposed for solving a multiple-sets split feasibility problem (MSFP), which is to find

$$
x \in \bigcap_{i=1}^{p} C_{i} \quad \text { such that } A x \in \bigcap_{j=1}^{r} Q_{j},
$$

where $p, r \geq 1$ are integers, $\left\{C_{i}\right\}_{i=1}^{p}$ and $\left\{Q_{j}\right\}_{j=1}^{r}$ are nonempty closed convex subsets of $H_{1}$ and $H_{2}$, respectively. When $p=r=1$, then MSFP (1.3) is known as SFP (1.1).

Since every closed convex subset of a Hilbert space is the fixed point set of its associating projection, the problem (1.1) and (1.3) are all special cases of the so-called multiple-set split common fixed point problem (MSCFP) which is to find

$$
x \in \bigcap_{i=1}^{p} \operatorname{Fix}\left(S_{i}\right) \quad \text { such that } A x \in \bigcap_{j=1}^{r} \operatorname{Fix}\left(T_{j}\right) \text {, }
$$

where $p, r \geq 1$ are integers, $\left\{S_{i}\right\}_{i=1}^{p}: H_{1} \rightarrow H_{1}$ and $\left\{T_{j}\right\}_{j=1}^{r}: H_{2} \rightarrow H_{2}$ are nonlinear operators and $\operatorname{Fix}\left(S_{i}\right)$ and $\operatorname{Fix}\left(T_{j}\right)$ are the sets of fixed points of $S_{i}$ and $T_{j}$, respectively. In particular, if $p=r=1$, then MSCFP (1.4) reduces to the split common fixed point problem (SCFP) $[11,20,27,29]$ to find

$$
x \in \operatorname{Fix}(S) \text { such that } A x \in \operatorname{Fix}(T) \text {, }
$$

where $S: H_{1} \rightarrow H_{1}$ and $T: H_{2} \rightarrow H_{2}$ are nonlinear operators.

It is easy to see from $[10,15]$ that the above problems are the special cases of the following problem:

find a point $x^{*} \in X$ that solves IP1

and such that

the point $y^{*}=A x^{*} \in Y$ solves IP2,

where IP1 and IP2 are inverse problems, which is called the split inverse problem (SIP).

Furthermore, we find that the equilibrium problem (EP) and the split variational inequality problem (SVI) are also special cases of SIP from [10, 11, 15, 21].

As the further extension of the split feasibility problem, Moudafi [22,23] introduced the split equality feasibility problem (SEFP) to find

$$
x \in C, \quad y \in Q \quad \text { such that } A x=B y,
$$


where $A: H_{1} \rightarrow H_{3}$ and $B: H_{2} \rightarrow H_{3}$ are two bounded linear operators. Obviously, if $B=I$ and $H_{3}=H_{2}$, then (1.6) reduces to (1.1), which can be extended to be the split common fixed point problem (SCFPP); see [11] and the references therein. This kind of split equality feasibility problem (1.6) allows for asymmetric and partial relations between the variables $x$ and $y$.

To solve the split equality feasibility problem (1.6), Moudafi [23] proposed the following alternating $C Q$ algorithm:

$$
\left\{\begin{array}{l}
x_{n+1}=P_{C}\left(x_{n}-\gamma_{n} A^{*}\left(A x_{n}-B y_{n}\right)\right), \\
y_{n+1}=P_{Q}\left(y_{n}+\gamma_{n} B^{*}\left(A x_{n+1}-B y_{n}\right)\right) .
\end{array}\right.
$$

Under suitable conditions, he proved the weak convergence of the sequence $\left\{\left(x_{n}, y_{n}\right)\right\}$ to a solution of (1.6) in Hilbert spaces. About the study of algorithms and theories for solving (1.6), the reader can also see $[14,17]$ and the references therein.

In [23], Moudafi studied the split equality common fixed point problem (SECFP), which is to find

$$
x \in \operatorname{Fix}(S), \quad y \in \operatorname{Fix}(T) \text { such that } A x=B y,
$$

and proposed the following iterative algorithm:

$$
\left\{\begin{array}{l}
x_{n+1}=S\left(x_{n}-\lambda_{n} A^{*}\left(A x_{n}-B y_{n}\right)\right), \\
y_{n+1}=T\left(y_{n}+\beta_{n} B^{*}\left(A x_{n+1}-B y_{n}\right)\right) .
\end{array}\right.
$$

He proved the weak convergence of the sequences generated by scheme (1.9) under the condition that $S$ and $T$ are firmly quasi-nonexpansive mappings. The study of the problem (1.9) not only has theory interesting, but also has practical background. In [1, 2], Attouch et al. propose the inertial Nash equilibration processes, which is the link with decision sciences and game theory. The problem can be modeled as the following convex optimization problem:

$$
\min \{f(x)+g(y)+\mu Q(x, y), x \in X, y \in Y\},
$$

where $X, Y$ are real Hilbert spaces, $f: X \rightarrow \mathbf{R} \cup\{+\infty\}, g: Y \rightarrow R \cup\{+\infty\}$ are closed convex proper functions acting, respectively, on the spaces $X$ and $Y, Q: X \times Y \rightarrow R^{+}$is a nonnegative quadratic form which couples the two variables $x$ and $y$, and $\mu$ is a positive parameter. Let $f(x)=\|x-z\|^{2}, g(y)=\|y-v\|^{2}$, and $Q(x, y)=\|A x-B y\|^{2}$, where $z \in \operatorname{fix}(S)$, $v \in \operatorname{fix}(T)$ and $S, T$ are operators. Then the optimization solution of the problem (1.10) is the solution of (1.8).

Furthermore, Chang, Wang and Qin [13] modified the iterative scheme (1.9) and provided a unified framework for solving this problem without using the projection. The framework is as follows:

$$
\left\{\begin{array}{l}
u_{n}=x_{n}-\gamma_{n} A^{*}\left(A x_{n}-B y_{n}\right), \\
x_{n+1}=\alpha_{n} x_{n}+\left(1-\alpha_{n}\right)[(1-\xi) I+\xi S((1-\eta) I+\eta S)] u_{n}, \\
v_{n}=y_{n}+\gamma_{n} B^{*}\left(A x_{n}-B y_{n}\right), \\
y_{n+1}=\alpha_{n} y_{n}+\left(1-\alpha_{n}\right)[(1-\xi) I+\xi T((1-\eta) I+\eta T)] v_{n},
\end{array}\right.
$$


where $S: H_{1} \rightarrow H_{1}$ and $T: H_{2} \rightarrow H_{2}$ are two L-Lipschitz and quasi-pseudo-contractive mappings with $L \geq 1, \operatorname{Fix}(T) \neq \emptyset$. They proved that the sequence $\left\{\left(x_{n}, y_{n}\right)\right\}$ generated by the above modification (1.11) converges weakly to a solution of problem (1.8).

In this paper, we propose an alternating iterative algorithm which modifies the iterative scheme (1.11). In the process of calculating $v_{n}$, we use $x_{n+1}$ instead of $x_{n}$. And we modify the directions $A^{*}\left(A x_{n}-B y_{n}\right)$ and $B^{*}\left(B y_{n}-A x_{n}\right)$, which can make full use of the current information of the iterative points. Details please see Theorem 3.1 in Sect. 3. Furthermore, we prove that the sequence generated by the algorithm weakly converges to a solution of the split equality common fixed point problem (1.8). Numerical results show that the feasibility and efficiency of this algorithm by comparing the algorithm proposed in this paper with the algorithm in [13].

\section{Preliminaries}

In this section, we recall some concepts, definitions and conclusions, which are prepared for proving our main results. We write $x_{n} \rightarrow x$ and $x_{n} \rightarrow x$ to indicate that the sequence $\left\{x_{n}\right\}$ converges weakly and strongly to $x$, respectively.

Definition 2.1 ([28]) A mapping $T: C \rightarrow C$ is called

(i) quasi-nonexpansive, if $\operatorname{Fix}(T) \neq \emptyset$ and

$$
\left\|T x-x^{*}\right\| \leq\left\|x-x^{*}\right\|, \quad \text { for all } x \in C \text { and } x^{*} \in \operatorname{Fix}(T) ;
$$

(ii) quasi-pseudo-contractive, if $\operatorname{Fix}(T) \neq \varnothing$ and

$$
\left\|T x-x^{*}\right\|^{2} \leq\left\|x-x^{*}\right\|^{2}+\|T x-x\|^{2}, \quad \text { for all } x \in C \text { and } x^{*} \in \operatorname{Fix}(T) .
$$

A mapping $P_{C}$ is said to be metric projection of $H_{1}$ onto $C$ if for every point $x \in H_{1}$, there exists a unique nearest point in $C$ denoted by $P_{C} x$ such that

$$
\left\|x-P_{C} x\right\| \leq\|x-y\|, \quad \text { for all } y \in C .
$$

The corresponding property of the mapping $P_{C}$ can be seen from [16]. Furthermore, the demiclosedness principle plays an important role in our arguments.

A mapping $T: H \rightarrow H$ is called demiclosed at the origin if for any sequence $\left\{x_{n}\right\}$ which weakly converges to $x$, and the sequence $\left\{T x_{n}\right\}$ strongly converges to 0 , then $T x=0$.

To establish the main results, we need the following technical lemmas.

Lemma 2.1 ([12]) Let $H$ be a real Hilbert space, then the following conclusions hold:

$$
\begin{aligned}
& \|x-y\|^{2}=\|x\|^{2}+\|y\|^{2}-2\langle x, y\rangle, \quad \forall x, y \in H, \\
& \begin{aligned}
\|\alpha x+(1-\alpha) y\|^{2}= & \alpha\|x\|^{2}+(1-\alpha)\|y\|^{2} \\
& -\alpha(1-\alpha)\|x-y\|, \quad \forall x, y \in H, \alpha \in[0,1] .
\end{aligned}
\end{aligned}
$$

Lemma 2.2 Let $H$ be a real Hilbert space and $T: H \rightarrow H$ be a L-Lipschitz mapping with $L \geq 1$. 
Denote

$$
K:=(1-\xi) I+\xi T((1-\eta) I+\eta T) .
$$

If $0<\xi<\eta<\frac{1}{1+\sqrt{1+L^{2}}}$, then the following conclusions hold:

(i) $\operatorname{Fix}(T)=\operatorname{Fix}(T((1-\eta) I+\eta T))=\operatorname{Fix}(K)$.

(ii) If $T$ is demiclosed at 0 , then $K$ is also demiclosed at 0.

(iii) In addition, if $T: H \rightarrow H$ is quasi-pseudo-contractive, then the mapping $K$ is quasi-nonexpansive, that is,

$$
\left\|K x-u^{*}\right\| \leq\left\|x-u^{*}\right\|, \quad \forall x \in H \text { and } u^{*} \in \operatorname{Fix}(T)=\operatorname{Fix}(K) .
$$

\section{Main results}

In this section, we assume that

(i) $H_{1}, H_{2}$ and $H_{3}$ are real Hilbert spaces. $A: H_{1} \rightarrow H_{3}$ and $B: H_{2} \rightarrow H_{3}$ are two bounded linear operators, $A^{*}$ and $B^{*}$ are their adjoint operators, respectively.

(ii) $S: H_{1} \rightarrow H_{1}$ and $T: H_{2} \rightarrow H_{2}$ are all L-Lipschitz and quasi-pseudo-contractive mapping with $L \geq 1,0<\xi_{n}<\eta_{n}<\frac{1}{1+\sqrt{1+L^{2}}}, \forall n \geq 1, \operatorname{Fix}(S) \neq \emptyset$, and $\operatorname{Fix}(T) \neq \emptyset$.

Our objective is to solve the split equality common fixed point problem to find

$$
x^{*} \in \operatorname{Fix}(S), \quad y^{*} \in \operatorname{Fix}(T) \quad \text { such that } A x^{*}=B y^{*} \text {. }
$$

Theorem 3.1 Let $H_{1}, H_{2}, H_{3}$ and $A, B, S, T$ are assumed as above. Assume that $\left\{\alpha_{n}\right\}$ is a non-increasing sequence which satisfies $0<\beta \leq \alpha_{n} \leq \theta<1$, where $\beta$ and $\theta$ are real numbers. For arbitrary $x_{0} \in H_{1}, y_{0} \in H_{2}$, let $\left\{x_{n}\right\},\left\{y_{n}\right\},\left\{u_{n}\right\}$ and $\left\{v_{n}\right\}$ be generated by

$$
\left\{\begin{array}{l}
u_{n}=x_{n}-\gamma_{n}\left[\left(x_{n}-K x_{n}\right)+A^{*}\left(A x_{n}-B y_{n}\right)\right] \\
x_{n+1}=\alpha_{n} x_{n}+\left(1-\alpha_{n}\right) K u_{n}, \\
v_{n}=y_{n}-\gamma_{n}\left[\left(y_{n}-G y_{n}\right)-B^{*}\left(A x_{n+1}-B y_{n}\right)\right] \\
y_{n+1}=\alpha_{n} y_{n}+\left(1-\alpha_{n}\right) G v_{n},
\end{array}\right.
$$

where

$$
\begin{aligned}
K & :=\left(1-\xi_{n}\right) I+\xi_{n} S\left(\left(1-\eta_{n}\right) I+\eta_{n} S\right), \\
G & :=\left(1-\xi_{n}\right) I+\xi_{n} T\left(\left(1-\eta_{n}\right) I+\eta_{n} T\right) .
\end{aligned}
$$

Assume $S$ and $T$ are demiclosed at 0 , and $\left\{\gamma_{n}\right\}$ is a non-decreasing sequence which satisfies

$$
\gamma_{n} \in\left(\varepsilon, \frac{1}{1+c}-\varepsilon\right), \quad c=\max \left\{\|A\|^{2},\|B\|^{2}\right\}
$$

where $\varepsilon$ is small enough. Then the sequence $\left\{\left(x_{n}, y_{n}\right)\right\}$ generated by the algorithm weakly converges to the solution of (3.1). 
Proof Choose $p \in \operatorname{Fix}(S), q \in \operatorname{Fix}(T)$ and $A p=B q$. By the algorithm of Theorem 3.1, we have

$$
\begin{aligned}
\left\|u_{n}-p\right\|^{2} & \\
= & \left\|x_{n}-\gamma_{n}\left[\left(x_{n}-K x_{n}\right)+A^{*}\left(A x_{n}-B y_{n}\right)\right]-p\right\|^{2} \\
= & \left\|x_{n}-p\right\|^{2}+\gamma_{n}^{2}\left\|\left(x_{n}-K x_{n}\right)+A^{*}\left(A x_{n}-B y_{n}\right)\right\|^{2} \\
& \quad-2 \gamma_{n}\left\langle x_{n}-p,\left(x_{n}-K x_{n}\right)+A^{*}\left(A x_{n}-B y_{n}\right)\right\rangle \\
\leq & \left\|x_{n}-p\right\|^{2}+\gamma_{n}^{2}\left(1+\|A\|^{2}\right)\left\|x_{n}-K x_{n}\right\|^{2}+\gamma_{n}^{2}\left(1+\frac{1}{\|A\|^{2}}\right)\left\|A^{*}\left(A x_{n}-B y_{n}\right)\right\|^{2} \\
& \quad-2 \gamma_{n}\left\langle x_{n}-p, x_{n}-K x_{n}\right\rangle-2 \gamma_{n}\left\langle x_{n}-p, A^{*}\left(A x_{n}-B y_{n}\right)\right\rangle .
\end{aligned}
$$

We have

$$
\begin{aligned}
& -2\left\langle x_{n}-p, x_{n}-K x_{n}\right\rangle \\
& \quad=-2\left\|x_{n}-p\right\|^{2}-2\left\langle x_{n}-p, p-K x_{n}\right\rangle \\
& \quad=-2\left\|x_{n}-p\right\|^{2}+\left\|x_{n}-p\right\|^{2}+\left\|K x_{n}-p\right\|^{2}-\left\|K x_{n}-x_{n}\right\|^{2} \\
& \quad \leq-\left\|K x_{n}-x_{n}\right\|^{2}, \\
& -2\left\langle A x_{n}-A p, A x_{n}-B y_{n}\right\rangle=\left\|B y_{n}-A p\right\|^{2}-\left\|A x_{n}-A p\right\|^{2}-\left\|A x_{n}-B y_{n}\right\|^{2} .
\end{aligned}
$$

Combining (3.4) and (3.5), then (3.3) can be written as

$$
\begin{aligned}
\| u_{n}- & p \|^{2} \\
\leq & \left\|x_{n}-p\right\|^{2}+\gamma_{n}^{2}\left(1+\|A\|^{2}\right)\left\|x_{n}-K x_{n}\right\|^{2}+\gamma_{n}^{2}\left(1+\|A\|^{2}\right)\left\|A x_{n}-B y_{n}\right\|^{2} \\
& -\gamma_{n}\left\|K x_{n}-x_{n}\right\|^{2}+\gamma_{n}\left\|B y_{n}-A p\right\|^{2}-\gamma_{n}\left\|A x_{n}-A p\right\|^{2} \\
& -\gamma_{n}\left\|A x_{n}-B y_{n}\right\|^{2} .
\end{aligned}
$$

Similarly, we can obtain

$$
\begin{aligned}
& \left\|v_{n}-q\right\|^{2} \\
& \leq\left\|y_{n}-q\right\|^{2}+\gamma_{n}^{2}\left(1+\|B\|^{2}\right)\left\|y_{n}-G y_{n}\right\|^{2}+\gamma_{n}^{2}\left(1+\|B\|^{2}\right)\left\|A x_{n+1}-B y_{n}\right\|^{2} \\
& \quad-\gamma_{n}\left\|G y_{n}-y_{n}\right\|^{2}+\gamma_{n}\left\|A x_{n+1}-B q\right\|^{2}-\gamma_{n}\left\|B y_{n}-B q\right\|^{2} \\
& \quad-\gamma_{n}\left\|A x_{n+1}-B y_{n}\right\|^{2} .
\end{aligned}
$$

Adding (3.6) and (3.7), by $A p=B q$, we have

$$
\begin{aligned}
\| u_{n}- & p\left\|^{2}+\right\| v_{n}-q \|^{2} \\
\leq & \left\|x_{n}-p\right\|^{2}+\left\|y_{n}-q\right\|^{2}-\gamma_{n}\left\|A x_{n}-A p\right\|^{2}+\gamma_{n}\left\|A x_{n+1}-A p\right\|^{2} \\
& -\gamma_{n}\left(1-\gamma_{n}\left(1+\|A\|^{2}\right)\right)\left\|K x_{n}-x_{n}\right\|^{2} \\
& -\gamma_{n}\left(1-\gamma_{n}\left(1+\|A\|^{2}\right)\right)\left\|A x_{n}-B y_{n}\right\|^{2}
\end{aligned}
$$




$$
\begin{aligned}
& -\gamma_{n}\left(1-\gamma_{n}\left(1+\|B\|^{2}\right)\right)\left\|G y_{n}-y_{n}\right\|^{2} \\
& -\gamma_{n}\left(1-\gamma_{n}\left(1+\|B\|^{2}\right)\right)\left\|A x_{n+1}-B y_{n}\right\|^{2} .
\end{aligned}
$$

By $K$ and $G$ being quasi-nonexpansive and Eq. (2.5), we can write

$$
\begin{aligned}
& \left\|x_{n+1}-p\right\|^{2} \\
& \quad=\left\|\alpha_{n} x_{n}+\left(1-\alpha_{n}\right) K u_{n}-p\right\|^{2} \\
& \quad=\left\|\alpha_{n}\left(x_{n}-p\right)+\left(1-\alpha_{n}\right)\left(K u_{n}-p\right)\right\|^{2} \\
& \quad=\alpha_{n}\left\|x_{n}-p\right\|^{2}+\left(1-\alpha_{n}\right)\left\|K u_{n}-p\right\|^{2}-\alpha_{n}\left(1-\alpha_{n}\right)\left\|K u_{n}-x_{n}\right\|^{2} \\
& \quad \leq \alpha_{n}\left\|x_{n}-p\right\|^{2}+\left(1-\alpha_{n}\right)\left\|u_{n}-p\right\|^{2}-\alpha_{n}\left(1-\alpha_{n}\right)\left\|K u_{n}-x_{n}\right\|^{2} .
\end{aligned}
$$

Similarly, we can obtain

$$
\begin{aligned}
& \left\|y_{n+1}-q\right\|^{2} \\
& \quad=\left\|\alpha_{n} y_{n}+\left(1-\alpha_{n}\right) G v_{n}-q\right\|^{2} \\
& \quad \leq \alpha_{n}\left\|y_{n}-q\right\|^{2}+\left(1-\alpha_{n}\right)\left\|v_{n}-q\right\|^{2}-\alpha_{n}\left(1-\alpha_{n}\right)\left\|G v_{n}-y_{n}\right\|^{2} .
\end{aligned}
$$

Adding (3.9) and (3.10), combining (3.8), we have

$$
\begin{aligned}
\| x_{n+1} & -p\left\|^{2}+\right\| y_{n+1}-q \|^{2} \\
\leq & \alpha_{n}\left[\left\|x_{n}-p\right\|^{2}+\left\|y_{n}-q\right\|^{2}\right]+\left(1-\alpha_{n}\right)\left[\left\|u_{n}-p\right\|^{2}+\left\|v_{n}-q\right\|^{2}\right] \\
& -\alpha_{n}\left(1-\alpha_{n}\right)\left[\left\|K u_{n}-x_{n}\right\|^{2}+\left\|G v_{n}-y_{n}\right\|^{2}\right] \\
\leq & \left\|x_{n}-p\right\|^{2}+\left\|y_{n}-q\right\|^{2}-\left(1-\alpha_{n}\right) \gamma_{n}\left\|A x_{n}-A p\right\|^{2} \\
& +\left(1-\alpha_{n}\right) \gamma_{n}\left\|A x_{n+1}-A p\right\|^{2} \\
& -\left(1-\alpha_{n}\right) \gamma_{n}\left(1-\gamma_{n}\left(1+\|A\|^{2}\right)\right)\left\|K x_{n}-x_{n}\right\|^{2} \\
& -\left(1-\alpha_{n}\right) \gamma_{n}\left(1-\gamma_{n}\left(1+\|A\|^{2}\right)\right)\left\|A x_{n}-B y_{n}\right\|^{2} \\
& -\left(1-\alpha_{n}\right) \gamma_{n}\left(1-\gamma_{n}\left(1+\|B\|^{2}\right)\right)\left\|G y_{n}-y_{n}\right\|^{2} \\
& -\left(1-\alpha_{n}\right) \gamma_{n}\left(1-\gamma_{n}\left(1+\|B\|^{2}\right)\right)\left\|A x_{n+1}-B y_{n}\right\|^{2} \\
& -\alpha_{n}\left(1-\alpha_{n}\right)\left[\left\|K u_{n}-x_{n}\right\|^{2}+\left\|G v_{n}-y_{n}\right\|^{2}\right] .
\end{aligned}
$$

\section{Letting}

$$
\Gamma_{n}(p, q)=\left\|x_{n}-p\right\|^{2}+\left\|y_{n}-q\right\|^{2}-\left(1-\alpha_{n}\right) \gamma_{n}\left\|A x_{n}-A p\right\|^{2} .
$$

From (3.11), $\left\{\alpha_{n}\right\}$ and $\left\{\gamma_{n}\right\}$ being non-increasing, we can get the following inequality:

$$
\begin{gathered}
\Gamma_{n+1}(p, q) \leq \Gamma_{n}(p, q)-\alpha_{n}\left(1-\alpha_{n}\right)\left[\left\|K u_{n}-x_{n}\right\|^{2}+\left\|G v_{n}-y_{n}\right\|^{2}\right] \\
-\left(1-\alpha_{n}\right) \gamma_{n}\left(1-\gamma_{n}\left(1+\|A\|^{2}\right)\right)\left\|K x_{n}-x_{n}\right\|^{2}
\end{gathered}
$$




$$
\begin{aligned}
& -\left(1-\alpha_{n}\right) \gamma_{n}\left(1-\gamma_{n}\left(1+\|A\|^{2}\right)\right)\left\|A x_{n}-B y_{n}\right\|^{2} \\
& -\left(1-\alpha_{n}\right) \gamma_{n}\left(1-\gamma_{n}\left(1+\|B\|^{2}\right)\right)\left\|G y_{n}-y_{n}\right\|^{2} \\
& -\left(1-\alpha_{n}\right) \gamma_{n}\left(1-\gamma_{n}\left(1+\|B\|^{2}\right)\right)\left\|A x_{n+1}-B y_{n}\right\|^{2} .
\end{aligned}
$$

From (3.12) and $\gamma_{n} \in\left(\varepsilon, \frac{1}{1+c}-\varepsilon\right), c=\max \left\{\|A\|^{2},\|B\|^{2}\right\}$, we have

$$
\Gamma_{n+1}(p, q) \leq \Gamma_{n}(p, q)
$$

and

$$
\Gamma_{n}(p, q) \geq\left[1-\left(1-\alpha_{n}\right) \gamma_{n}\|A\|^{2}\right]\left\|x_{n}-p\right\|^{2}+\left\|y_{n}-q\right\|^{2} \geq 0 .
$$

Therefore, the sequence $\left\{\Gamma_{n}(p, q)\right\}$ is a non-increasing sequence and lower bounded by 0 . As a result, $\left\{\Gamma_{n}(p, q)\right\}$ converges to some finite limit. Suppose that is $\Gamma\left(x^{*}, y^{*}\right)$. Hence, we know that the sequences $\left\{x_{n}\right\}$ and $\left\{y_{n}\right\}$ are bounded. Letting $n \rightarrow \infty$ and taking the limit in the two sides of (3.12), we obtain

$$
\begin{aligned}
\left\|K u_{n}-x_{n}\right\| \rightarrow 0 ; & \left\|K x_{n}-x_{n}\right\| \rightarrow 0 ; & \left\|A x_{n}-B y_{n}\right\| \rightarrow 0 \\
\left\|G v_{n}-y_{n}\right\| \rightarrow 0 ; & \left\|G y_{n}-y_{n}\right\| \rightarrow 0 ; & \left\|A x_{n+1}-B y_{n}\right\| \rightarrow 0 .
\end{aligned}
$$

Now, let us prove that $\left\{x_{n}\right\}$ and $\left\{y_{n}\right\}$ are asymptotically regular, from (3.13), we can obtain

$$
\begin{aligned}
\lim _{n \rightarrow \infty}\left\|x_{n+1}-x_{n}\right\| & =\lim _{n \rightarrow \infty}\left\|\alpha_{n} x_{n}+\left(1-\alpha_{n}\right) K u_{n}-x_{n}\right\| \\
& =\lim _{n \rightarrow \infty}\left\|-\left(1-\alpha_{n}\right) x_{n}+\left(1-\alpha_{n}\right) K u_{n}\right\| \\
& =\lim _{n \rightarrow \infty}\left(1-\alpha_{n}\right)\left\|K u_{n}-x_{n}\right\|=0 .
\end{aligned}
$$

Similarly, we have

$$
\lim _{n \rightarrow \infty}\left\|y_{n+1}-y_{n}\right\|=0 .
$$

From (3.13), we have

$$
\begin{aligned}
\lim _{n \rightarrow \infty}\left\|u_{n}-x_{n}\right\| & =\lim _{n \rightarrow \infty} \gamma_{n}\left\|\left(x_{n}-K x_{n}\right)+A^{*}\left(A x_{n}-B y_{n}\right)\right\| \\
& \leq \lim _{n \rightarrow \infty}\left[\gamma_{n}\left\|x_{n}-K x_{n}\right\|+\gamma_{n}\left\|A^{*}\left(A x_{n}-B y_{n}\right)\right\|\right] \\
& \leq \lim _{n \rightarrow \infty}\left[\left\|x_{n}-K x_{n}\right\|+\gamma_{n}\|A\|\left\|A x_{n}-B y_{n}\right\|\right]=0 .
\end{aligned}
$$

Similarly, we can obtain

$$
\lim _{n \rightarrow \infty}\left\|v_{n}-y_{n}\right\|=0 .
$$

Combining (3.13), (3.14) and (3.15), we can get

$$
\begin{aligned}
& \lim _{n \rightarrow \infty}\left\|K u_{n}-u_{n}\right\|=\lim _{n \rightarrow \infty}\left[\left\|K u_{n}-x_{n}\right\|+\left\|x_{n}-u_{n}\right\|\right]=0, \\
& \lim _{n \rightarrow \infty}\left\|G v_{n}-v_{n}\right\|=\lim _{n \rightarrow \infty}\left[\left\|G v_{n}-y_{n}\right\|+\left\|y_{n}-v_{n}\right\|\right]=0 .
\end{aligned}
$$


Since $\left\{x_{n}\right\}$ and $\left\{y_{n}\right\}$ are bounded sequences, there exist weakly convergent subsequences, say $\left\{x_{n_{j}}\right\} \subset\left\{x_{n}\right\}$ and $\left\{y_{n_{j}}\right\} \subset\left\{y_{n}\right\}$ such that $x_{n_{j}} \rightarrow x^{*}$ and $y_{n_{j}} \rightarrow y^{*}$. The Opial property guarantees that the weakly subsequential limit of $\left\{\left(x_{n}, y_{n}\right)\right\}$ is unique. So we have $x_{n} \rightarrow x^{*}$ and $y_{n} \rightarrow y^{*}$.

On the other hand, from (3.14) and (3.15), we can obtain $u_{n} \rightarrow x^{*}$ and $v_{n} \rightarrow y^{*}$. Since $K$ and $G$ are demiclosed at 0 and by (3.16), we have $K x^{*}=x^{*}$ and $G y^{*}=y^{*}$, which imply that $x^{*} \in \operatorname{Fix}(K)$ and $y^{*} \in \operatorname{Fix}(G)$, that is, $x^{*} \in \operatorname{Fix}(S)$ and $y^{*} \in \operatorname{Fix}(T)$ from Lemma 2.2(i).

Furthermore, since $A x_{n}-B y_{n} \rightarrow A x^{*}-B y^{*}$, by using the weakly lower-continuity of the squared norm, we have

$$
\left\|A x^{*}-B y^{*}\right\|^{2}=\liminf _{n \rightarrow \infty}\left\|A x_{n}-B y_{n}\right\|^{2} \leq \lim _{n \rightarrow \infty}\left\|A x_{n}-B y_{n}\right\|^{2}=0 .
$$

consequently, $A x^{*}=B y^{*}$. The proof is completed.

\section{Numerical examples}

In this section, we give an example to show some insight into the behavior of the algorithm presented in this paper. The whole codes are written in Matlab 7.0. All the numerical results are carried out on a personal Lenovo Thinkpad computer with Intel(R) Core(TM) i7-6500U CPU $2.50 \mathrm{GHz}$ and RAM 8.00 GB.

Example 4.1 Let $H_{1}=H_{2}=H_{3}=R^{5} . S(x)=\frac{1}{5} \sin x, T(x)=\frac{1}{10} \sin x . A \in R^{5 \times 5}, B \in R^{5 \times 5}$ are as follows:

$$
\begin{aligned}
A & =\left(\begin{array}{lllll}
0.6674 & 0.4429 & 0.1642 & 0.0410 & 0.1124 \\
0.9138 & 0.8919 & 0.1286 & 0.1953 & 0.9165 \\
0.5186 & 0.0535 & 0.4354 & 0.6849 & 0.2078 \\
0.6941 & 0.7589 & 0.9198 & 0.0316 & 0.0625 \\
0.3730 & 0.9534 & 0.1759 & 0.3807 & 0.2593
\end{array}\right), \\
B & =\left(\begin{array}{lllll}
0.4654 & 0.2709 & 0.1099 & 0.3647 & 0.0556 \\
0.8159 & 0.4763 & 0.0070 & 0.4048 & 0.3070 \\
0.3713 & 0.6759 & 0.6937 & 0.9897 & 0.7612 \\
0.1701 & 0.5584 & 0.5488 & 0.5779 & 0.1563 \\
0.2222 & 0.1778 & 0.9335 & 0.6102 & 0.8083
\end{array}\right) .
\end{aligned}
$$

The problem is to find $x^{*} \in \operatorname{Fix}(S), y^{*} \in \operatorname{Fix}(T)$ such that $A x^{*}=B y^{*}$.

In the experiments, we take $\alpha_{n}=\frac{1}{3}+\frac{1}{2^{n}}, \xi_{n}=\left(1-\left(\frac{1}{2}\right)^{n}\right) * \frac{1}{1+\sqrt{1+L^{2}}}, \eta_{n}=\left(1-\left(\frac{2}{3}\right)^{n}\right) * \frac{1}{1+\sqrt{1+L^{2}}}$, where $L$ is not higher than the minimum value of the Lipschitzian constants of $S$ and $T$. In this example, we set $L=\sqrt{5}$. Set $\gamma_{n}=\min \left\{\frac{1}{1+\lambda_{A}}, \frac{1}{1+\lambda_{B}}\right\} / 1.01$. The stopping criterion is $\left\|A x_{n}-B y_{n}\right\| \leq 10^{-6}$.

In the following tables and figures, we denote the non-alternating iteration algorithm in [13] and the alternating iteration algorithm in this paper for solving split equality common fixed point problem by "NAIA" and "AIA", respectively. And we set " $k$ ", " $s$ ", " $x^{*}$ " and " $y$ " to express the number of iteration, CPU time in seconds and the final solution, respectively. Init. denotes the initial points. The numerical results can be seen from Tables 1 and 2 .

Furthermore, for testing the stationary property of iterative number, we carry out 500 experiments for different initial points which are presented randomly, such as 
Table 1 The numerical results of Example 4.1

\begin{tabular}{ll}
\hline Init. & $x^{0}=(0.8263,0.7819,0.4906,0.1597,0.5815)^{T}$ \\
& $y^{0}=(0.4197,0.3410,0.2918,0.4596,0.3053)^{T}$ \\
NAIA & $k=65, s=0.1250$ \\
& $x^{*}=(0.3636,0.7099,0.8712,0.5159,0.4564)^{T} * 10^{-5}$ \\
& $y^{*}=(0.4151,0.6644,0.8149,0.5041,0.4949)^{T} * 10^{-5}$ \\
AIA $\quad$ & $k=58, s=0.1121$ \\
& $x^{*}=(0.1219,-0.1458,0.0677,0.0801,0.1676)^{T} * 10^{-5}$ \\
& $y^{*}=(0.1093,0.0727,-0.0224,0.0301,-0.0147)^{T} * 10^{-5}$ \\
\hline
\end{tabular}

Table 2 The numerical results of Example 4.1

\begin{tabular}{ll}
\hline Init. & $x^{0}=(3.0492,4.3746,2.7310,5.8945,2.7787)^{T}$ \\
& $y^{0}=(8.0905,6.3501,3.7049,7.1736,3.5388)^{T}$ \\
NAIA & $k=77, s=0.1426$ \\
& $x^{*}=(0.0423,0.0058,0.0288,0.1143,0.0084)^{T} * 10^{-4}$ \\
& $y^{*}=(0.4186,0.3893,0.2041,0.3560,0.2168)^{T} * 10^{-5}$ \\
AIA & $k=70, s=0.1315$ \\
& $x^{*}=(0.0091,-0.0117,0.0375,0.2795,0.0268)^{T} * 10^{-5}$ \\
& $y^{*}=(0.4038,0.2972,0.2596,0.3781,0.5171)^{T} * 10^{-6}$ \\
\hline
\end{tabular}
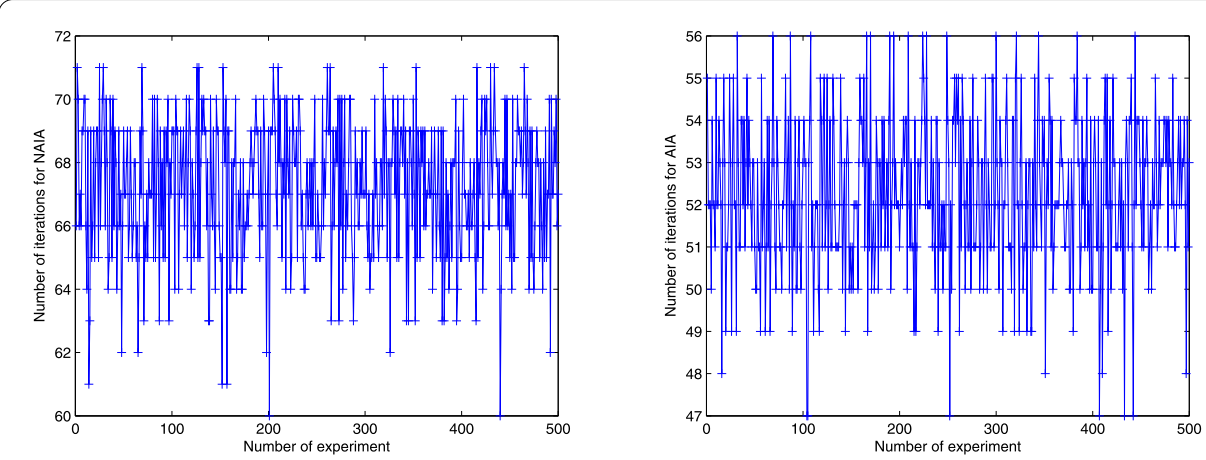

Figure 1 The iterative number of NAIA and AIA for the initial point of Case 1
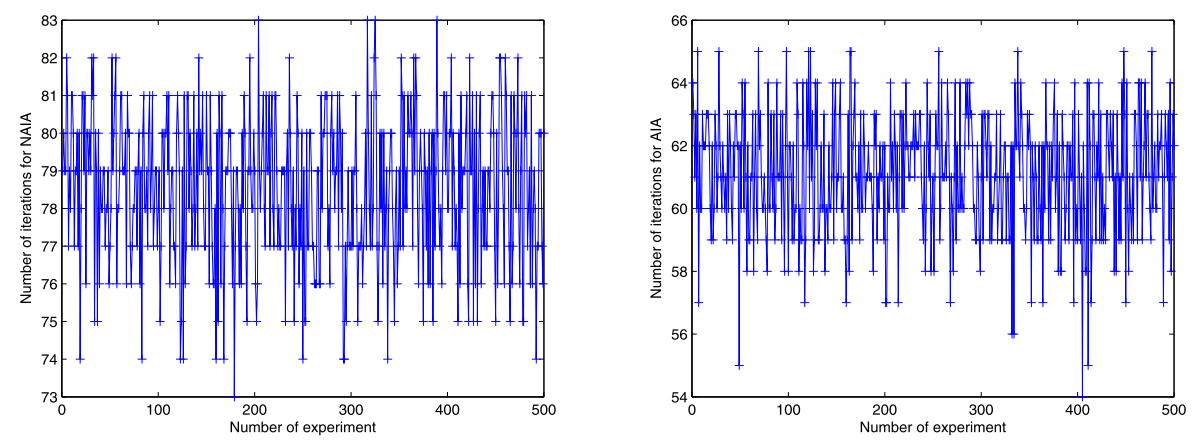

Figure 2 The iterative number of NAIA and AIA for the initial point of Case 2

Case 1. $x^{0}=\operatorname{rand}(5,1), y^{0}=\operatorname{rand}(5,1)$;

Case 2. $x^{0}=\operatorname{rand}(5,1) * 10, y^{0}=\operatorname{rand}(5,1) * 10$;

Case 3. $x^{0}=\operatorname{rand}(5,1) * 100, y^{0}=\operatorname{rand}(5,1) * 100$; 

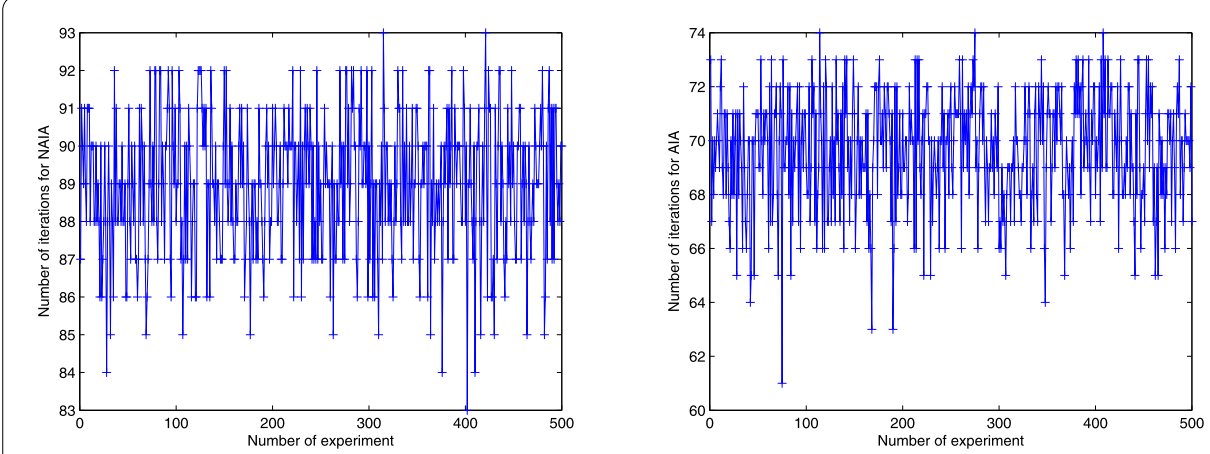

Figure 3 The iterative number of NAIA and AIA for the initial point of Case 3
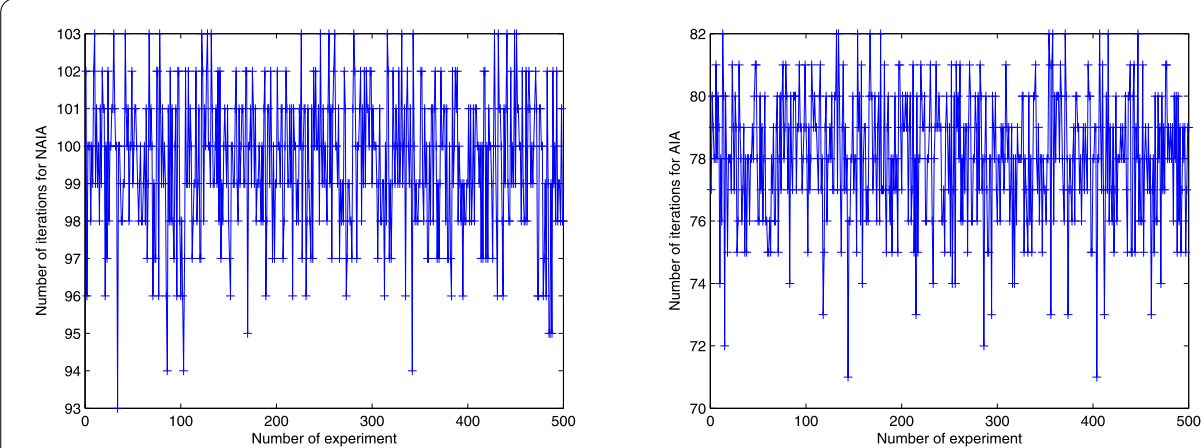

Figure 4 The iterative number of NAIA and AIA for the initial point of Case 4

Case 4. $x^{0}=\operatorname{rand}(5,1) * 1000, y^{0}=\operatorname{rand}(5,1) * 1000$,

separately in Example 4.1, the results can be found in Figs. 1-4.

From Tables 1 and 2 and Figs. 1-4, we can see that the iterative number and CPU time of the alternating iteration algorithm in this paper are smaller than that of the nonalternating iteration algorithm in [13].

\section{Conclusions}

In this paper, we study the split equality common fixed point problem and propose an alternating iteration algorithm for solving this problem. We prove the weak convergence of the iteration sequence generated by the alternating iteration algorithm. At the same time, we solve a numerical example using the non-alternating iteration algorithm presented in [13] and the alternating iteration algorithm proposed in this paper. From the numerical results, we can see that the alternating iteration algorithm is superior to the non-alternating iteration algorithm with respect to the iterative number and CPU time for the example. Certainly, more examples are needed for validation.

\section{Acknowledgements}

We thank the anonymous referees and the editor for their constructive comments and suggestions, which greatly improved this article.

\section{Funding}

This work is supported by the Natural Science Foundation of China (Grant Nos. 11401438, 11571120) and Shandong Provincial Natural Science Foundation (Grant No. ZR2017LA002, ZR2019MA022) and the Project of Shandong Province Higher Educational Science and Technology Program (Grant No. J14LI52). 
Availability of data and materials

All data generated or analysed during this study are included in this manuscript.

\section{Competing interests}

The authors declare that they have no competing interests regarding the present manuscript.

\section{Authors' contributions}

All authors contributed equally to the writing of this paper. All authors read and approved the final manuscript.

\section{Author details}

'School of Mathematics and Information Science, Weifang University, Weifang, P.R. China. ${ }^{2}$ College of Mathematics and Systems Science, Shandong University of Science and Technology, Qingdao, P.R. China.

\section{Publisher's Note}

Springer Nature remains neutral with regard to jurisdictional claims in published maps and institutional affiliations.

Received: 29 March 2019 Accepted:6 September 2019 Published online: 18 September 2019

\section{References}

1. Attouch, H., Bolte, J., Redont, P., Soubeyran, A.: Alternating proximal algorithms for weakly coupled minimization problems. Applications to dynamical games and PDE's. J. Convex Anal. 28, 39-44 (2008)

2. Attouch, H., Redont, P., Soubeyran, A.: A new class of alternating proximal minimization algorithms with costs-to-move. SIAM J. Optim. 18, 1061-1081 (2007)

3. Bauschke, H., Borwein, J.: On projection algorithms for solving convex feasibility problems. SIAM Rev. 38, 367-426 (1996)

4. Byrne, C.: Iterative oblique projection onto convex sets and the split feasibility problem. Inverse Probl. 18, 441-453 (2002)

5. Byrne, $C$ :: A unified treatment of some iterative algorithms in signal processing and image reconstruction. Inverse Probl. 20, 103-120 (2004)

6. Cegielski, A., Reich, S., Zalas, R.: Weak, strong and linear convergence of the CQ-method via the regularity of Landweber operators. Optimization (2019). https://doi.org/10.1080/02331934.2019.1598407

7. Censor, Y., Bortfeld, T., Martin, B., Trofimov, A.: A unified approach for inversion problems in intensity-modulated radiation therapy. Phys. Med. Biol. 51, 2353-2365 (2006)

8. Censor, Y., Elfving, T.: A multiprojection algorithm using Bregman projections in a product space. Numer. Algorithms 8, 221-239 (1994)

9. Censor, Y., Elfving, T., Kopf, N., Bortfeld, T.: The multi-sets split feasibility problem and its applications for inverse problems. Inverse Probl. 21, 2071-2084 (2005)

10. Censor, Y., Gibali, A., Reich, S.: Algorithms for the split variational inequality problem. Numer. Algorithms 59, 301-323 (2012)

11. Censor, Y., Segal, A.: The split common fixed point problem for directed operators. J. Convex Anal. 16, 587-600 (2009)

12. Chang, S.: Some problems and results in the study of nonlinear analysis. Nonlinear Anal. 30, 4197-4208 (1997)

13. Chang, S., Wang, L., Qin, L.: Split equality fixed point problem for quasi-pseudo-contractive mappings with applications. Fixed Point Theory Appl. 2015, Article ID 208 (2015)

14. Che, H., Li, M.: A simultaneous iterative method for split equality problems of two finite families of strictly pseudononspreading mappings without prior knowledge of operator norms. Fixed Point Theory Appl. 2015, Article ID 1 (2015)

15. Gibali, A.: A new split inverse problem and application to least intensity feasible solutions. Pure Appl. Funct. Anal. 2 , 243-258 (2017)

16. Goebel, K., Reich, S.: Uniform Convexity, Hyperbolic Geometry, and Nonexpansive Mappings. Dekker, New York (1984)

17. Li, M., Kao, X., Che, H.: A simultaneous iteration algorithm for solving extended split equality fixed point problem. Math. Probl. Eng. 2017, Article ID 9737062 (2017)

18. Liu, B., Qu, B., Zheng, N.: A successive projection algorithm for solving the multiple-sets split feasibility problem Numer. Funct. Anal. Optim. 35, 1459-1466 (2014)

19. Masad, E., Reich, S.: A note on the multiple-set split convex feasibility problem in Hilbert space. J. Nonlinear Convex Anal. 8, 367-371 (2007)

20. Moudafi, A.: A note on the split common fixed-point problem for quasi-nonexpansive operators. Nonlinear Anal. 74 4083-4087 (2011)

21. Moudafi, A.: Split monotone variational inclusions. J. Optim. Theory Appl. 150, 275-283 (2011)

22. Moudafi, A.: A relaxed alternating CQ-algorithm for convex feasibility problems. Nonlinear Anal. 79, 117-121 (2013)

23. Moudafi, A.: Alternating CQ-algorithm for convex feasibility and split fixed-point problems. J. Nonlinear Convex Anal. 15, 809-818 (2014)

24. Qu, B., Chang, H.: Remark on the successive projection algorithm for the multiple-sets split feasibility problem. Numer. Funct. Anal. Optim. 38, 1614-1623 (2017)

25. Qu, B., Liu, B., Zheng, N.: On the computation of the step-size for the CQ-like algorithms for the split feasibility problem. Appl. Math. Comput. 262, 218-223 (2015)

26. Qu, B., Xiu, N.: A new halfspace-relaxation projection method for the split feasibility problem. Linear Algebra Appl. $428,1218-1229(2008)$

27. Reich, S., Tuyen, T.: A new algorithm for solving the split common null point problem in Hilbert spaces. Numer. Algorithms (2019). https://doi.org/10.1007/s11075-019-00703-z

28. Sankatha, S., Bruce, W., Pramila, S.: Fixed Point Theory and Best Approximation: The KKM-Map Principle. Kluwe Academic, Dordecht (1998) 
29. Tang, Y., Liu, L.: Several iterative algorithms for solving the split common fixed point problem of directed operators with applications. Optimization 65, 53-65 (2016)

30. Wang, X:: Alternating proximal penalization algorithm for the modified multiple-set split feasibility problems. J. Inequal. Appl. 2018, Article ID 48 (2018)

31. Xu, H.: A variable Krasnoselski-Mann algorithm and the multiple-set split feasibility problem. Inverse Probl. 22, 2021-2034 (2006)

32. Xu, H.: Iterative methods for the split feasibility problem in infinite-dimensional Hilbert spaces. Inverse Probl. 26 5018-5034 (2008)

33. Yang, Q.: The relaxed CQ algorithm solving the split feasibility problem. Inverse Probl. 20, 1261-1266 (2004)

34. Yao, Y., Chen, R., Marino, G., Liou, Y.: Applications of fixed point and optimization methods to the multiple-sets split feasibility problem. Appl. Math. 2012, 359-373 (2012)

35. Zhang, H., Wang, Y.: A new CQ method for solving split feasibility problem. Front. Math. China 5, 37-46 (2010)

Submit your manuscript to a SpringerOpen ${ }^{\circ}$ journal and benefit from:

- Convenient online submission

Rigorous peer review

- Open access: articles freely available online

- High visibility within the field

- Retaining the copyright to your article

Submit your next manuscript at $\mathbf{s p r i n g e r o p e n . c o m ~}$ 